\title{
The effects of oral gabapentin premedication on the incidence of postoperative nausea and vomiting and early postoperative recovery profile in paediatric patients undergoing adenotonsillectomy
}

\author{
Nassar H., Abdulatif M., El-Adawy A., Wahba S. \\ Cairo University, Dept of Anaesthesiology \& Intensive Care, Cairo, Egypt
}

Background and Goal of Study:

Current evidence suggests that gabapentin reduces the incidence of postoperative nausea and vomiting (PONV) in adults. The antiemetic potentials of gabapentin in paediatric patients were not systematically investigated before. This double-blind, randomised, controlled study was designed to explore the effects of oral gabapentin premedication on the incidence of PONV, on children behavior during inhalation induction of anaesthesia, and on the early recovery profile of paediatric patients undergoing adenotonsillectomy in the day surgery unit. Materials and methods:

The study included 140 patients (3-12 years) randomised to receive oral gabapentin $16 \mathrm{mg} / \mathrm{kg}(\mathrm{n}=70)$ or placebo $(\mathrm{n}=70)$ as premedication; $2 \mathrm{~h}$ before anaesthesia. All patients received a standard anaesthetic including: sevoflurane, fentanyl $1 \mu \mathrm{g} / \mathrm{kg}$, and rectal acetaminophen 30 $\mathrm{mg} / \mathrm{kg}$. Patients were breathing spontaneously. The Paediatric Anaesthesia Behaviour score (PAB) was used to assess patients acceptance of inhalation induction. The following parameters were recorded by a blinded investigator over the $6 \mathrm{~h}$ study period: time to extubation and interaction, composite incidence of PONV, incidence of emergence agitation (EA) using Cole and Paediatric Anaesthesia Emergence Delirium (PAED) scores, Objective pain scale (OPS), and the time to first request to postoperative analgesia. Primary outcome of the study is the incidence of PONV. The trial was registered in the Clinical Trials.gov (NCT02384187).

Results and discussion:

Patients characteristics were comparable in the two groups. The incidence of PONV was $13 \%$ in gabapentin group compared to $28 \%$ in the control, ( $\mathrm{p}$ 0.03) (table 1). Relative risk reduction, absolute risk reduction, and the number needed to treat for PONV were 0.55, 0.16, and 6 , respectively. The incidence of EA was lower at all times assessment points during the first hour postoperatively in gabapentin group (table 2). PAB score during inhalation induction, time to extubation and interaction, OPS, and time to first request to rescue postoperative analgesia were comparable in the two groups (table 1). Gabapentin use was not associated with any observed side effects.

Table 1:Pediatric Anesthesia Behavior score (PAB score) during inhalation induction of anesthesia, recovery characteristics and incidence of postoperative nausea and vomiting (PONV). Data are presented as mean (SD), number (\%), and median (IQR).

\begin{tabular}{|c|c|c|c|}
\hline & $\begin{array}{l}\text { Gabapentin } \\
n=70\end{array}$ & $\begin{array}{l}\text { Control } \\
\mathbf{n}=\mathbf{7 0}\end{array}$ & P value \\
\hline $\begin{array}{l}\text { PAB score } \\
\begin{array}{l}\text { - } \\
\text { - } 2 \\
\text { - } 3\end{array}\end{array}$ & $\begin{array}{l}32(46 \%) \\
32(46 \%) \\
6(8 \%)\end{array}$ & $\begin{array}{l}41(59 \%) \\
21(30 \% 0 \\
8(11 \%)\end{array}$ & $\begin{array}{l}0.2 \\
0.3 \\
0.2\end{array}$ \\
\hline $\begin{array}{l}\text { Median } \quad \text { PAB } \\
\text { score }\end{array}$ & $2(1-2)$ & $1(1-2)$ & 0.2 \\
\hline $\begin{array}{l}\text { Time to } \\
\text { extubation(min) }\end{array}$ & $4.2(1.8)$ & $4.5(2.3)$ & 0.3 \\
\hline $\begin{array}{l}\text { Time to } \\
\text { interaction(min) }\end{array}$ & 4.9 (1.9) & $5.4(2.4)$ & 0.2 \\
\hline $\begin{array}{l}\text { Time to rescue } \\
\text { analgesic(min) }\end{array}$ & $42.1(30)$ & $48.5(37)$ & 0.5 \\
\hline $\begin{array}{l}\text { Incidence of } \\
\text { PONV }\end{array}$ & $9(13 \%)$ & $20(28 \%)$ & 0.03 \\
\hline
\end{tabular}

Table 2: Postoperative Pediatric Anesthesia Emergence Delirium (PAED) score Data are presented as median (IQR)

\begin{tabular}{|l|l|l|l|} 
& $\begin{array}{l}\text { Gabapentin } \\
\mathbf{n = 7 0}\end{array}$ & $\begin{array}{l}\text { Control } \\
\mathbf{n = 7 0}\end{array}$ & P value \\
\hline $10 \mathrm{~min}$ & $10(8-12) *$ & $10(9-12)$ & 0.02 \\
\hline $20 \mathrm{~min}$ & $6(5-7) *$ & $8(6-9)$ & 0.01 \\
\hline $30 \mathrm{~min}$ & $2(2-5) *$ & $5(2-7)$ & 0.009 \\
\hline $40 \mathrm{~min}$ & $1(0-3) *$ & $4(2-5)$ & 0.0 \\
\hline $50 \mathrm{~min}$ & $1(0-1) *$ & $3(2-4)$ & 0.0 \\
\hline $60 \mathrm{~min}$ & $0(0-1) *$ & $2(1-3)$ & 0.0 \\
\hline
\end{tabular}

Conclusion(s):

The use of oral gabapentin premedication in paediatric patients undergoing adenotonsillectomies under sevoflurane anaesthesia reduces the incidence of PONV and EA in the early postoperative period. However gabapentin does not appear to have postoperative analgesic effects in this patient population. 